individual's treatability in the community. Leave is granted until the date of a future community acute service clinical meeting when a team decision is made and the ward

original papers

informed. For individuals still detained under the Mental Health Act, the community acute service consultant then becomes the responsible clinician.

\section{Discussion}

We know that home treatment is an effective intervention $^{2}$ and reduces hospital admission rates by about $23 \%$ for 24 -hour services. ${ }^{3}$ Additionally, home treatment is generally preferred by patients. ${ }^{2}$ Similarly, we know that certain carefully selected individuals with severe mental illness improve more quickly in a day hospital than if cared for as an in-patient ${ }^{4}$ and that acute day hospitals provide greater patient satisfaction than in-patient care, at least in the short-term. ${ }^{5}$

One of Marshall's ${ }^{6}$ proposals for developing day hospital care was to combine it with outreach services for people who fail to attend. Our model has started from the same 'structures' but our philosophical approach has been to tailor the care to what patients value most. Working as one team, the crisis and home treatment team and the acute day hospital are able to design flexible care plans, switching easily between modalities of care with minimal bureaucracy, creating a whole much larger than the sum of its parts.

From a service management point of view, the team is now fulfilling its service level agreement; increased efficiency has also facilitated a reduction of in-patient beds. Early polling suggests high user satisfaction and the team is committed to collecting continuous feedback through market research-style questionnaires; these will be used to inform future improvements. One of the areas we are currently working on is improving the interface with other services.

\section{Acknowledgements}

We thank Dr M. Stoffels, specialist registrar, for her help with this paper.

\section{Declaration of interest}

S.M. runs his own company, which works specifically with mental health services to improve their performance.

\section{References}

1 Department of Health. The Mental Health Policy Implementation Guidelines. Department of Health, 2001.

2 Smyth MJ, Hoult J. The home treatment enigma. BMJ 2000; 320; $305-9$

3 Glover G, Arts G, Babu KS. Crisis resolution/home treatment teams and psychiatric admission rates in England. BrJ Psychiatry 2006; 189: 441-5.

4 Marshall M, Crowther R, AlmarezSerrano A, Creed F, SledgeW,

Kluiter $\mathrm{H}$, et al. Day hospital versus admission for acute psychiatric disorders. Cochrane Database Syst Rev 2003; 1: CD004026.

5 Priebe $\mathrm{S}$, Jones $\mathrm{G}, \mathrm{McC}$ abe $\mathrm{R}$, Briscoe J, Wright D, Sleed $M$, et al. Effectiveness and costs of acute day hospital treatment compared with conventional in-patient care. Randomised controlled trial. $\mathrm{BrJ}$ Psychiatry 2006; 188: 243-9.

6 Marshall M. Acute psychiatric day hospitals. BMJ 2003; 327 $116-7$

*Danny Allen Consultant Psychiatrist, Oxfordshire \& Buckinghamshire Menta Health Partnership NHS Trust, Harlow House, Harlow Road, HighWycombe HP13 6AA, email: danny.allen@obmh.nhs.uk, Wendy Blaylock Service Manager, CommunityAcute Service, Oxfordshire \& Buckinghamshire Mental Health Partnership NHS Trust, Stefan Mieczkowski Operations Management Consultant, Archipelago Healthcare Ltd, Sutton Scotney, Winchester

JUN XIA, CLIVE ADAMS, NISHANT BHAGAT, VINAYA BHAGAT,

PARANTHAMAN BHOOPATHI, HANY EL-SAYEH, VANESSA PINFOLD AND YAHYA TAKRITI

\title{
Losing participants before the trial ends erodes credibility of findings
}

\section{AIMS AND METHOD}

To estimate the proportion of attrition at which results of drug trials for people with schizophrenia lose enough credibility to become mistrusted by relevant groups of stakeholders. A piloted questionnaire was sent to 128 local clinicians, 100 relevant researchers and 104 service users and carers.

\section{RESULTS}

We received the biggest number of responses from the service user and carer group $(n=81,76 \%) ; 43 \%$ of clinicians and $32 \%$ of researchers responded. All three groups suggested that the follow-up rate for a 12-week schizophrenia drug trial should be around $70-75 \%$ for the trial to be credible.

\section{CLINICAL IMPLICATIONS}

This survey suggests that relevant stakeholders, including researchers, fundamentally mistrust results of the majority of drug trials in schizophrenia. Adopting a more pragmatic trial design can help address this.
Randomised controlled trials relevant to people with schizophrenia are often small and of short duration. ${ }^{1,2}$ Attrition rates from these studies can be considerable (Table 1). Whatever the reason for the loss of trial sample to follow-up, whether it is because the participant requests it or because trial protocol necessitates withdrawal from the study, these people often are not able to provide, or are not available for, final outcome scores. 
Although some complete information may still be obtained from routine data, this loss to follow-up does mean that many scale-derived outcomes reflect the condition of only a proportion of participants. As scale data are so commonly the primary outcomes in trials relevant to mental healthcare, ${ }^{2}$ this leaves these studies vulnerable to the many biases introduced by not undertaking an intention-to-treat analysis. ${ }^{3}$ Statistical techniques have evolved to rebuild a semblance of the complete data-set but all such devices are imperfect and are based on assumptions that are difficult or impossible to substantiate. ${ }^{4,5}$

We aimed to gauge the attrition level at which results of drug trials for people with schizophrenia lose enough credibility to be mistrusted by three relevant groups of stakeholders.

\section{Method}

A protocol was written and power calculations undertaken, suggesting that for what we thought would be a meaningful difference (20\%) about 100 people in each of the groups would be necessary ( $\alpha=0.05$, power $80 \%$ ). The questionnaire was drawn up and piloted in groups of clinicians, researchers and mental health service users (this led to refinement of the accompanying background information and of the final questionnaire question; see the online supplement to this paper). In March 2007, three groups of stakeholders were targeted. First, email contacts of all 128 general adult psychiatrists within the Yorkshire Deanery were obtained (the clinicians). Then a list of the first 100 most recently published email contacts from within the Cochrane Schizophrenia Group's Register of trials was generated (the researchers). Finally, 104 carers/service users from Rethink's regional groups across England were contacted (Rethink is a leading UK mental health membership charity, www.rethink.org). The trial gained approval from Leeds East Research Ethics Committee and one follow-up email was allowed should there be no response on first contact. On 23 March 2007, the question (see online supplement) was sent to the clinicians and researchers via email and followed up 2 months later. During this period, questionnaires were also sent out to carers and service users who attend Rethink's regional governance meetings.

\section{Results}

Response rates from clinicians and researchers were poor but all three stakeholder groups estimated the proportion of follow-up sample necessary at 12 weeks to

Table 1. Total lost to follow-up by about 10-12 weeks in drug trials ${ }^{1}$

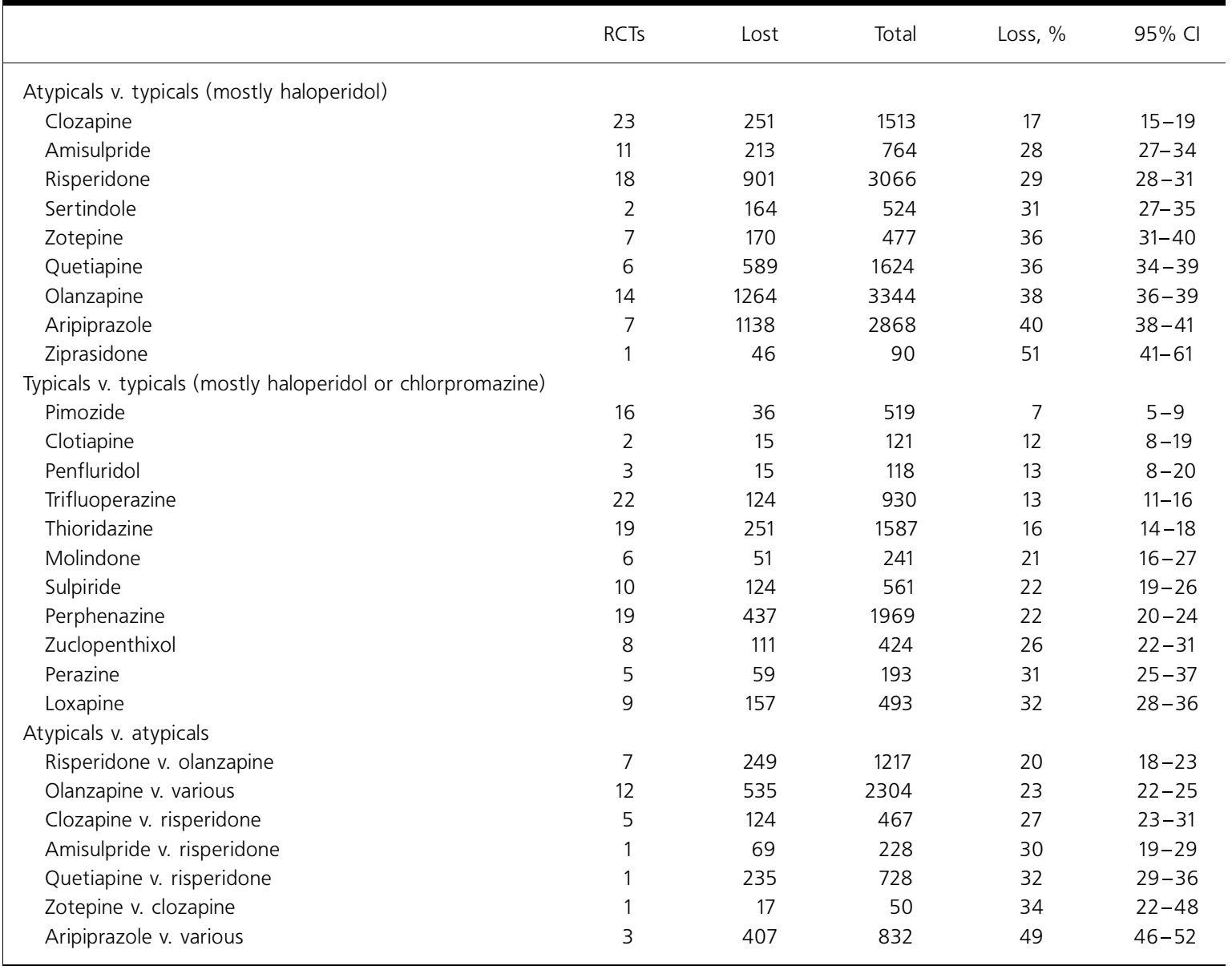

$\mathrm{RCT}$, randomised controlled trial.

1. Source of data - relevant Cochrane reviews. 


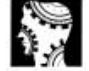

original

papers generate a basic level of trust in the outcomes in drug trials relevant to schizophrenia to be about $70-80 \%$ (Table 2).

\section{Discussion}

This is the result of a survey with variable response rate to a question that forced a binary decision in a situation that, in reality, usually involves managing degrees of discomfort with research findings. It is also feasible that a question with well-tested psychometric properties may have generated different results. Nevertheless, we know of no study in any area of healthcare that has even attempted to investigate this limit of credibility in those for whom results of trials are important. Using $70-80 \%$ follow-up at 12 weeks as a broad estimate of the limit of credibility on the data derived from trials (Table 1) shows that the evidence on many commonly used drugs falls short of this standard.

To put this finding in context, schizophrenia drug trials are often short, involve participants who are so rigorously diagnosed as to be difficult to find in everyday practice, prescribe interventions that demand rigid adherence and measure outcomes on many scales of variable quality ${ }^{6}$ that are often reported poorly and are problematic to interpret clinically. ${ }^{2}$ These studies, nevertheless, are the well-established gold standard means by which mental health treatments are evaluated. ${ }^{7}$ This simple survey asked participants to put aside all other worries about the design, conduct and reporting of these studies and to focus on attrition. Investigation of this single variable undermines the credibility of outcomes in most studies.

Drug trials, however, often report several outcomes. Attrition from one outcome may be large, whereas other outcome data from within the same study are almost complete. Often data on outcomes such as 'loss to follow-up', 'hospitalised' or 'in contact with services/ police/family' are reasonably complete and it is not surprising that major trials are now beginning to use these as primary outcomes. ${ }^{8}$ This choice of simple routine outcomes, however, is still the exception rather than the rule. Most trials in this area focus on fine-grain, scalederived outcomes. Scales, although greatly valued nonphysiological measures, are mostly ordinal rather than continuous and face problems with validity, analysis and interpretation. They are further undermined by their association with incomplete data-sets. Often, however, trials generate binary outcomes such as 'improved to an important degree', but these are based on incomplete scale data and fail to directly ask the simple single question that would cover this outcome and for which it is likely that much more complete and credible data could be acquired.

\section{Conclusions}

Currently, clinicians, policy makers and consumers of care have to come to decisions about treatments based on information that is of questionable credibility. We believe
Table 2. Response rates and credibility rate as viewed by three groups of stakeholders

\begin{tabular}{lcc} 
& $\begin{array}{c}\text { Follow-up } \\
\text { necessary for } \\
\text { Responses, } n / N \\
(\%)\end{array}$ & $\begin{array}{c}\text { credibility, mean } \\
(95 \% \mathrm{Cl})\end{array}$ \\
\hline $\begin{array}{l}\text { Clinicians } \\
\text { Researchers }\end{array}$ & $55 / 128(43)$ & $75.3(\mathrm{Cl} 72-78)$ \\
Carers & $32 / 100(32)$ & $76.4(\mathrm{Cl} 73-80)$ \\
$81 / 104(76)$ & $70.8(\mathrm{Cl} 67-74)$
\end{tabular}

$n$, responded; $N$, total number approached.

that this allows many factors, such as fashion and advertising, to take priority over good evidence when it comes to making the difficult decisions about care. The loss of people from these studies is both an enormous opportunity and waste. One method used to give a semblance of end-point ratings is to carry forward the last observation of the person before they left. Ratings, even from the first few weeks into the trial, are carried forward to the end of the study, perhaps months later, often with the (unlikely) assumption that the person has been stable since the point of departure. If this technique remains acceptable to users of the findings, there will be little motivation for improvement. Last-observationcarried-forward is a flawed technique that depends on considerable assumptions and can lead to erroneous results. ${ }^{9}$ The study design that wastes the resource of willing people ensures that most trials in schizophrenia remain small and difficult to apply clinically. There is now accumulating evidence that using more routine data can generate high-grade data-sets even on protracted followup. ${ }^{10}$ Simpler pragmatic/real-world design could ensure that more studies were adequately powered for the more complete data-sets of clinically meaningful outcomes.

\section{Acknowledgements}

The survey was supported by the National Health Service Priorities and Needs.

\section{Declaration of interest}

None.

\section{References}

1 Cure SJ, Adams CE. Forensic trials inform the present and future. $\mathrm{Br}$ Psychiatry 2000; 177: 182

2 Thornley B, Adams C. Content and quality of 2000 controlled trials in schizophrenia over 50 years. BMJ 1998; 317: 1181-4.

3 Hollis S, Campbell, F. What is meant by intention to treat analysis? Survey of published randomised controlled trials. BMJ 1999; 319: $670-4$
4 Dunn G, Maracy M, Tomenson B. Estimating treatment effects from randomised clinical trials with noncompliance and loss to follow-up: the role of instrumental variable methods. Stat Methods Med Res 2005; 14: 369-95.

5 Leucht S, Engel RR, Bauml J, Davis $J M$. Is the superior efficacy of new generation antipsychotics an artifact of LOCF? Schizophr Bull 2007; 33: 183-91. 


\begin{tabular}{|c|c|}
\hline $\begin{array}{l}6 \text { Marshall M, Lockwood A, Bradley } \\
\text { C, Adams C, Joy C, Fenton M. } \\
\text { Unpublished rating scales: a major } \\
\text { source of bias in randomised } \\
\text { controlled trials of treatments for } \\
\text { schizo-phrenia. BrJ Psychiatry }\end{array}$ & $\begin{array}{l}8 \text { Lieberman JA, StroupTS, McEvoyJP, } \\
\text { Swartz MS, Rosenheck RA, Perkins } \\
\text { DO, et al. Effectiveness of } \\
\text { antipsychotic drugs in patients with } \\
\text { chronic schizophrenia. N Engl J Med } \\
\text { 2005; 353: 1209-23. }\end{array}$ \\
\hline $\begin{array}{l}7 \text { WHO Scientific Group on } \\
\text { Treatment of Psychiatric Disorders. } \\
\text { Evaluation of Methods for the } \\
\text { Treatment of Mental Disorders. } \\
\text { World Health Organization, 1991. }\end{array}$ & $\begin{array}{l}9 \text { Cotton SM, Yuen HP, Berger G, } \\
\text { McGorry P. Last observation } \\
\text { carried forward in psychiatric } \\
\text { research - a flawed gold } \\
\text { standard. Aust N Z J Psychiatry } \\
\text { 2005; 39: } 622 \text {. }\end{array}$ \\
\hline
\end{tabular}
10 Bain MRS, Chalmers JWT, Brewster DH. Routinely collected data in national and regional
databases - an underused resource. J Public Health Med 1997; 19: $413-8$.

* Jun Xia Research Associate, Cochrane Schizophrenia Group, 2nd Floor, Bridge House, Balm Road, Leeds LS10 2TP, email: jun.xia@nottingham.ac.uk, Clive Adams Chair of Mental Health Services Research, University of Nottingham, Cochrane Schizophrenia Group, Nottingham, Nishant Bhagat Specialty Registrar (Year 3) in Psychiatry, Vinaya Bhagat Specialty Registrar (Year 3) in Psychiatry, Paranthaman Bhoopathi Consultant Psychiatrist, Hany El-Sayeh Consultant Psychiatrist, Cochrane Schizophrenia Group, Nottingham, Vanessa Pinfold Deputy Director of Knowledge and Learning, Rethink, London, Yahya Takriti Consultant in Old Age Psychiatry, Cochrane Schizophrenia Group, Nottingham

\section{SHAHEEN SHORA， ELIZABETH STONE AND KERON FLETCHER}

\section{Substance use disorders and psychological trauma}

\section{AIMS AND METHOD}

The Impact of Events Scale was administered to 104 in-patients detoxing from alcohol or opiates to determine the prevalence of psychological trauma, the severity of its symptoms and the types of trauma responsible for symptoms.
RESULTS

Out of the 104 in-patients undergoing detoxification, 75 had symptoms of psychological trauma; in 60 patients the symptoms were in the treatable range. Patients with alcohol-dependence were more severely affected. 'Life events' traumatised a higher proportion of individuals than 'traumatic events'.

\begin{abstract}
CLINICAL IMPLICATIONS
Psychological trauma requiring treatment is commonly found in substance misusers. This is rarely addressed despite the cormorbid disorder running a complicated clinical course. There are conflicting opinions about best practice, but consideration should be given to providing patients with accessible treatments for psychological trauma.
\end{abstract}

There are strong associations between substance misuse and psychological trauma. According to one US study, 3\% of substance misusers in the general population have post-traumatic stress disorder (PTSD). ${ }^{1}$ Rates of PTSD in female substance misusers on in-patient units rise to $42.5 \%{ }^{2}$ and to $62 \%$ for pregnant women treated in a residential setting. ${ }^{3}$ In the UK, rates of PTSD on in-patient substance misuse units have been reported at 38.5\% for current PTSD and at $51.9 \%$ for lifetime PTSD. ${ }^{4}$ Surveys of adolescent substance misusers report PTSD rates of up to $19.2 \% .^{5}$

In civilian populations without PTSD, rates of lifetime substance misuse range from 8.1 to $24.7 \%$, but in those with PTSD the levels rise to $21.6-43.0 \% .^{6-8}$ Up to $75 \%$ of US and UK war veterans with PTSD meet the criteria for alcohol misuse or dependence. ${ }^{9,10}$

Individuals with comorbid substance misuse and PTSD are more likely to have other psychiatric diagnoses, higher rates of psychosocial and physical problems, higher rates of in-patient admissions for substance misuse and higher rates of relapse compared with substance misusers without PTSD. 8,11

Within the general population, estimates of childhood sexual abuse in women are around $21-22 \%$ and in men $7-15 \%{ }^{12,13}$ However, childhood sexual abuse levels among substance misusers on in-patient detoxification units range from 49 to $67 \%$ for women and $12-33 \%$ for men. ${ }^{14-16}$

The association between substance misuse and psychological trauma is therefore important, not only because of the frequency of comorbidity and the additional complexity of the presentation, but also because of the more complicated clinical course and poorer prognosis.

This paper presents the results of a survey of 104 individuals with alcohol or opiate dependence who were undergoing a detoxification at New House Drug and Alcohol Unit, Shrewsbury, Shropshire. The survey sought to identify the number of individuals who were currently affected by symptoms of psychological trauma, to assess the severity of any psychological trauma using the Impact of Events Scale (IES), ${ }^{17,18}$ and to identify and describe the sorts of events that patients considered to be responsible for the development of their psychological trauma symptoms. Implications for the management of these individuals are discussed in the light of research findings and the National Institute for Health and Clinical Excellence (NICE) guidelines for the management of PTSD. $^{19}$

\section{Method}

All individuals who participated in this survey had given informed consent. A total of 104 in-patients with alcohol or opiate dependence undergoing detoxification were assessed for current symptoms of psychological trauma using the Impact of Events Scale (IES). This instrument was administered when patients were no longer experiencing any acute symptoms of alcohol or opiate 